\title{
Intrinsic Fluorescence Studies of Metal Ion Binding Effects on the Thermodynamic Stability of Human $\alpha$-Lactalbumin
}

\author{
James Jisuk Suh, Ruben M. Savizky* \\ Department of Chemistry, The Cooper Union for the Advancement of Science and Art 41 Cooper Square, New York, NY, 10003, USA
}

\begin{abstract}
The stability of the protein human $\alpha$-lactalbumin (HLA) after binding a series of metal cations $\left(\mathrm{Mg}^{2+}, \mathrm{Zn}^{2+}, \mathrm{Cd}^{2+}\right.$, $\mathrm{Co}^{2+}, \mathrm{Mn}^{2+}, \mathrm{Sr}^{2+}, \mathrm{Ca}^{2+}, \mathrm{Na}^{+}$and $\mathrm{K}^{+}$) has been examined and compared with that of $\alpha$-lactalbumin from other species by monitoring the fluorescence of tryptophan residues upon thermal-induced denaturation. The melting temperature $\left(\mathrm{T}_{\mathrm{m}}\right)$ was determined from the wavelength shift in $\lambda_{\max }$ data as well as the fluorescence intensity data as the protein unfolds. Mathematical expressions for determining thermodynamic parameters $(\Delta \mathrm{H}, \Delta \mathrm{G}$ and $\Delta \mathrm{S})$ were introduced based on the assumption that the thermal denaturing process was a simple two-state model between the folded state and the unfolded state. These newly developed expressions are especially useful because they allow one to easily calculate the thermodynamic parameters at every temperature as long as the fitting parameters are known. The thermal-induced unfolding experiments revealed that the binding of metal ions to apo- $\alpha$-lactalbumin increased its stability, but the degree of stabilization varied significantly for each metal ion. From the $\lambda_{\max }$ data and the fluorescence intensity data, the melting temperatures ranged from $28.15^{\circ} \mathrm{C}$ to

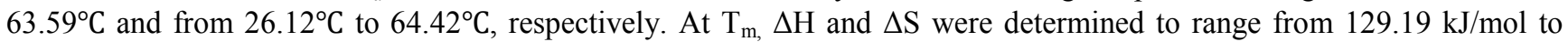
$273.69 \mathrm{~kJ} / \mathrm{mol}$ and from $0.40 \mathrm{~kJ} / \mathrm{mol} \cdot \mathrm{K}$ to $0.81 \mathrm{~kJ} / \mathrm{mol} \cdot \mathrm{K}$, respectively. At physiological temperature $\left(37^{\circ} \mathrm{C}\right), \Delta \mathrm{H}$ and $\Delta \mathrm{S}$ were determined to range from $121.84 \mathrm{~kJ} / \mathrm{mol}$ to $238.65 \mathrm{~kJ} / \mathrm{mol}$ and from $0.38 \mathrm{~kJ} / \mathrm{mol} \cdot \mathrm{K}$ to $0.68 \mathrm{~kJ} / \mathrm{mol} \cdot \mathrm{K}$, respectively. At $\mathrm{T}_{\mathrm{m}}, \Delta \mathrm{G}$ was 0 as expected, but it ranged from $-5.29 \mathrm{~kJ} / \mathrm{mol}$ to $19.91 \mathrm{~kJ} / \mathrm{mol}$ at $37^{\circ} \mathrm{C}$. Overall, the monovalent cations $\mathrm{Na}^{+}$and $\mathrm{K}^{+}$were found to destabilize HLA whereas the divalent cations $\mathrm{Mg}^{2+}, \mathrm{Zn}^{2+}, \mathrm{Cd}^{2+}, \mathrm{Co}^{2+}, \mathrm{Mn}^{2+}, \mathrm{Sr}^{2+}$ and $\mathrm{Ca}^{2+}$ were found to stabilize HLA. As $\alpha$-lactalbumin is a $\mathrm{Ca}^{2+}$-binding protein, $\mathrm{Ca}^{2+}$ was found to have the greatest effect on the protein stability with the $\mathrm{T}_{\mathrm{m}}$ value of $63.59^{\circ} \mathrm{C}$.
\end{abstract}

Keywords Protein Folding, Metalloprotein, Thermal Denaturation, Fluorescence Spectroscopy

\section{Introduction}

$\alpha$-lactalbumin is an acidic, globular protein that is produced in mammary glands during lactogenesis[1]. With a molecular weight of $14 \mathrm{kD}$ and an isoelectric point of 4-5, it is made up of 123 amino acid residues except for variants in rabbit and rat, which contain 122 and 140 residues, respectively[2]. Its native structure is made up of two lobes: the $\alpha$-domain (residues 1-34 and 86-123) consisting of four $\alpha$-helices and two short 310 -helices, and the $\beta$-domain (residues 35-85) consisting of a triple-stranded antiparallel $\beta$-sheet, one $3_{10}$-helix and a series of loops[1]. One of the most interesting characteristics of $\alpha$-lactalbumin is its ability to bind metal cations. It possesses a single distinct $\mathrm{Ca}^{2+}$ high affinity binding site which also binds other physiologically important metal cations including $\mathrm{Mg}^{2+}, \mathrm{Mn}^{2+}, \mathrm{Na}^{+}$

* Corresponding author:

rsavizky@cooper.edu (Ruben M. Savizky)

Published online at http://journal.sapub.org/biophysics

Copyright (C) 2011 Scientific \& Academic Publishing. All Rights Reserved and $\mathrm{K}^{+}$, and several distinct $\mathrm{Zn}^{2+}$ binding sites[3]. The binding of metal ions increases its stability against the action of heat and various denaturing factors such as urea and guanidine hydrochloride and has been extensively studied[4-9] in bovine and goat $\alpha$-lactalbumin (BLA and GLA). From these studies, it was found that a series of divalent metal ions including $\mathrm{Cd}^{2+}, \mathrm{Sr}^{2+}, \mathrm{Mn}^{2+}, \mathrm{Zn}^{2+}, \mathrm{Mg}^{2+}, \mathrm{Co}^{2+}$, $\mathrm{Ca}^{2+}$ and monovalent metal ions such as $\mathrm{Na}^{+}$and $\mathrm{K}^{+}$influence the conformation, stability and activity of $\alpha$ - lactalbumin upon binding, but the degree of stabilization varied for each metal cation. It is therefore reasonable to study the ability of human $\alpha$-lactalbumin (HLA) to bind these metal ions.

\section{Materials and Methods}

All chemicals were purchased from Sigma-Aldrich. All solutions were made using deionized water. Human $\alpha$-lactalbumin in a lyophilized form with $95 \%$ purity was used. The buffer solution was prepared from Tris-HCl. For melting experiments of each metal ion, ultrapure trace metal 
basis anhydrous $\mathrm{CaCl}_{2}, \mathrm{ZnCl}_{2}, \mathrm{MgCl}_{2}, \mathrm{MnCl}_{2}, \mathrm{CoCl}_{2}, \mathrm{CdCl}_{2}$ and $\mathrm{SrCl}_{2}$ with purity of $99.99 \%$ or higher were used and stored in a dessicator. For $\mathrm{pH}$ adjustment, $0.1 \mathrm{~N} \mathrm{HCl}$ and $0.1 \mathrm{~N} \mathrm{NaOH}$ standards were used.

Only plastic labware was used for sample preparation and storage except for a graduated cylinder and a dialysis beaker which were treated with trace metal grade nitric acid $(68 \sim 70 \%)$ to remove any trace contaminants prior to use. For demetallation procedures, ethylenediaminetetraacetic acid (EDTA) and Chelex-100 chelating ion exchange resin were used.

\subsection{Buffer Solutions}

Deionized water was first treated with Chelex-100 chelating ion exchange resin prior to use to remove any trace metal ions or impurities present. Chelex-100 was applied using a batch method where the addition of resin was directly made into the sample followed by stirring. This method was found to be extremely useful when the amount of sample was small. Approximately 5 grams of resin was used for every $100 \mathrm{~mL}$ of sample to be chelated. The mixture was then periodically swirled for about an hour, and the sample was carefully decanted out from the resin into a brand-new plastic container.

This treated water was then used for preparing $20 \mathrm{mM}$ Tris-HCl buffer solution. In order to simulate physiological conditions, the $\mathrm{pH}$ was adjusted to approximately 7.5 by titrating with $0.1 \mathrm{~N} \mathrm{HCl}$. An Accumet Basic (AB15 PLUS) $\mathrm{pH}$ meter manufactured by Fisher Scientific was utilized for the $\mathrm{pH}$ adjustment.

\subsection{HLA Solutions/Demetallation}

A $19.8 \mu \mathrm{M}$ human $\alpha$-lactalbumin (HLA) solution in 20 $\mathrm{mM}$ Tris- $\mathrm{HCl}$ buffer was prepared. Calcium metal ions bound to HLA were removed to obtain the apo form by mixing with $1 \mathrm{mM}$ EDTA solution in a 1:1 volume ratio. All the chelated metal ions present in the mixture were separated by dialyzing against $20 \mathrm{mM}$ Tris- $\mathrm{HCl}$ buffer solution. The dialysis device used for the separation process was Float-A-Lyzer G2 by Spectrum Laboratories. Its capacity was $5 \mathrm{~mL}$ for each dialysis run and had a 3.5-5 kD MWCO. Approximately $300 \mathrm{~mL}$ of the dialysate was used for each 5 $\mathrm{mL}$ of HLA / EDTA solution. For best results, the dialysate was replaced with a fresh batch of the same buffer solution three times over the course of a day and then left overnight at room temperature on a stir plate at $350 \mathrm{rpm}$ using a StableTemp stirring hot plate manufactured by Cole-Parmer. After the dialysis was finished, apo-HLA solution that was left in the dialysis bag was transferred to multiple $0.5 \mathrm{~mL}$ Eppendorf tubes in aliquots of $0.26 \mathrm{~mL}$ in order to minimize the number of freeze-thaw cycles. After each dialysis, apo-HLA was confirmed and characterized by fluorescence spectroscopy as shown in Figure 1. The solid spectrum (blue) is apo-HLA and the dashed spectrum (red) is $\mathrm{Ca}^{2+}$-saturated HLA. The results are in agreement with those obtained using BLA by Murakami et al. [3].

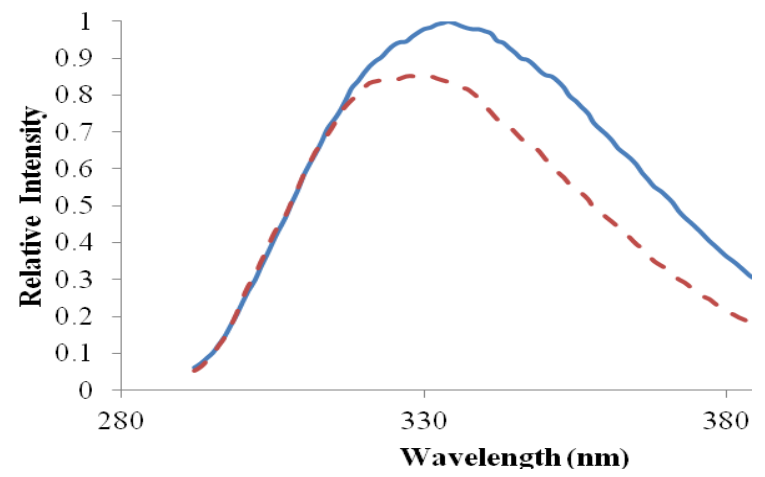

Figure 1. Intrinsic fluorescence spectra for characterization of apo-HLA (solid blue line) and $\mathrm{Ca}^{2+}$-saturated HLA (dashed red line)

\subsection{Metal Chloride Solutions}

$1 \mathrm{mM}$ solutions of $\mathrm{MgCl}_{2}, \mathrm{ZnCl}_{2}, \mathrm{CdCl}_{2}, \mathrm{CoCl}_{2}, \mathrm{MnCl}_{2}$, $\mathrm{SrCl}_{2}, \mathrm{CaCl}_{2}, \mathrm{NaCl}$ and $\mathrm{KCl}$ were each prepared in $20 \mathrm{mM}$ Tris- $\mathrm{HCl}$ buffer.

\subsection{Fluorescence Measurements}

Fluorescence measurements were carried out using a Varian Eclipse fluorescence spectrophotometer. The spectra were recorded using a $10 \mathrm{~mm}$ by $10 \mathrm{~mm}$ semi-micro cuvette with an excitation wavelength of $280 \mathrm{~nm}$ and an emission wavelength ranging between $290 \mathrm{~nm}$ and $400 \mathrm{~nm}$. Both the excitation and emission slit widths were set to $5 \mathrm{~mm}$, and the voltage was adjusted to $700 \mathrm{~V}$. The scan rate and the signal averaging time during data collection were set to be medium $(600 \mathrm{~nm} / \mathrm{min}$ ) and 0.1 second, respectively. The data interval was set to $1.0 \mathrm{~nm}$. Under these conditions, the fluorescence intensity and noise-to-signal ratio were optimized. Furthermore, the Savitzky-Golay smoothing algorithm (using 5 points) was employed in order to obtain additional noise reduction with sharp peaks.

A single-cell Peltier block was thermostated by circulating water from an external water bath (PCB 150 water bath). Fluorescence measurements were carried out at predetermined fixed temperatures depending on the experiment. The rate of the cuvette heating was timed using a stopwatch at approximately $1^{\circ} \mathrm{C}$ per minute. For fluorescence measurements, $500 \mu \mathrm{L}$ of sample $(250 \mu \mathrm{L}$ of a metal chloride solution and $250 \mu \mathrm{L}$ of apo-HLA) was used. For fluorescence measurements of apo-HLA, a solution containing $250 \mu \mathrm{L}$ of the Tris- $\mathrm{HCl}$ buffer solution and $250 \mu \mathrm{L}$ of apo-HLA was used. Prior to each scan, the spectrum was zeroed. For every newly prepared sample, the cuvette was thoroughly washed with the concentrated cuvette cleaner and was dried with compressed air. Non-linear regression analysis and curve-fitting were performed using Microcal Origin 8.0.

\section{Results}

Thermal denaturation was monitored via the wavelength shift in intrinsic tryptophan fluorescence for apo-HLA as well as for apo-HLA with a saturating amount of different 
metal ions $\left(\mathrm{Mg}^{2+}, \mathrm{Zn}^{2+}, \mathrm{Cd}^{2+}, \mathrm{Co}^{2+}, \mathrm{Mn}^{2+}, \mathrm{Sr}^{2+}, \mathrm{Ca}^{2+}, \mathrm{Na}^{+}\right.$and $\left.\mathrm{K}^{+}\right)$. The temperature range was from $5^{\circ} \mathrm{C}$ to $65^{\circ} \mathrm{C}-85^{\circ} \mathrm{C}$, and the same sample was scanned four times separately but successively in order to confirm that the thermal equilibrium was reached at each temperature. The results of this experiment for apo-HLA are shown in Figure 2, and for the addition of nine different metal ions in Figure 3.

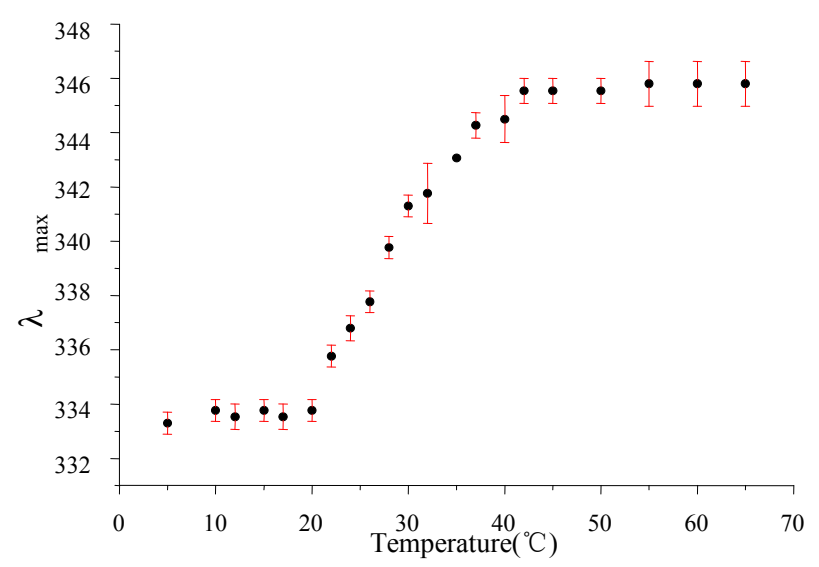

Figure 2. Temperature dependence of tryptophan $\lambda_{\max }$ for $0.5 \mathrm{~mL}$ of $5 \mu \mathrm{M}$ apo-HLA

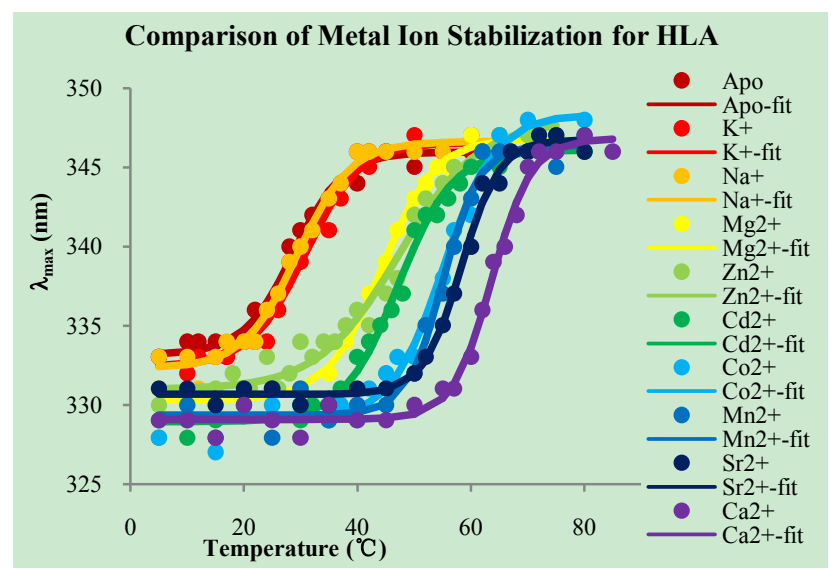

Figure 3. Temperature dependence of tryptophan $\lambda_{\max }$ for $0.25 \mathrm{~mL}$ of 10 $\mu \mathrm{M}$ apo-HLA $+0.25 \mathrm{~mL}$ of $1 \mathrm{mM}$ metal chloride solutions

As an alternative, the intensity data as a function of temperature could be used to find the melting temperature (Section 3.2). Assuming a two-state model (folded state $\rightleftharpoons$ unfolded state), the midpoint of the transition between the folded and the unfolded forms represents the melting temperature $\left(T_{m}\right)$ of the protein. At this melting temperature, there is a 1:1 mixture of folded molecules and unfolded molecules. The melting temperature can be found by fitting the data into the dose-response equation. Since the protein denaturation processes produced a sigmoidal curve, the following mathematical dose-response relationship was used for the non-linear curve fitting of the data from fluorescence measurements:

$$
y=A_{1}+\frac{A_{2}-A_{1}}{1+10^{\left(\log x_{0}-x\right) \cdot p}}
$$

$A_{1}$ and $A_{2}$ represent the bottom asymptote (folded state) and top asymptote (unfolded state), respectively, $\log x_{0}$ is the parameter for the melting temperature $\left(\mathrm{T}_{\mathrm{m}}\right)$ which is at the middle of the transition, and $\mathrm{p}$ is the Hill coefficient. Using this dose-response equation, expressions for the thermodynamic parameters $(\Delta H, \Delta \mathrm{G}$ and $\Delta \mathrm{S})$ of the conformation change upon thermal denaturation were derived (see Section 3.1). The results of this derivation are summarized in Table 1.

Table 1. Summary of mathematical expressions for derived thermodynamic parameters

\begin{tabular}{|c|c|}
\hline Thermodynamic Parameter & Mathematical Expression \\
\hline$\Delta \mathrm{H}(\mathrm{J} / \mathrm{mol})$ & $\Delta \mathrm{H}=2.303 \mathrm{RT}^{2} \mathrm{p}$ \\
\hline$\Delta \mathrm{G}(\mathrm{J} / \mathrm{mol})$ & $\Delta \mathrm{G}=2.303 R T p\left(\mathrm{~T}_{\mathrm{m}}-\mathrm{T}\right)$ \\
\hline$\Delta \mathrm{S}\left(\mathrm{J} / \mathrm{mol}{ }^{*} \mathrm{~K}\right)$ & $\Delta \mathrm{S}=2.303 R \mathrm{Rp}\left(2 \mathrm{~T}_{\mathrm{m}}-\mathrm{T}\right)$ \\
\hline
\end{tabular}

A summary of thermodynamic parameters (average melting temperature $\left(\mathrm{T}_{\mathrm{m}}\right), \Delta \mathrm{H}, \Delta \mathrm{G}$ and $\Delta \mathrm{S}$ ) determined from each experiment is presented in Tables 2 and 3. The calculations for $\Delta \mathrm{H}, \Delta \mathrm{G}$ and $\Delta \mathrm{S}$ were performed at $37^{\circ} \mathrm{C}$.

Table 2. Experimentally determined melting temperatures for apo-HLA and metal-ion bound HLA

\begin{tabular}{|c|c|c|}
\hline Experiment & $\mathrm{T}_{\mathrm{m}}\left({ }^{\circ} \mathrm{C}\right)-\lambda_{\max }$ data & $\mathrm{T}_{\mathrm{m}}\left({ }^{\circ} \mathrm{C}\right)-$ intensity data \\
\hline Apo-HLA & $28.15 \pm 0.58$ & 26.12 \\
\hline $\mathrm{MgCl}_{2}+$ apo-HLA & $44.31 \pm 0.41$ & 42.21 \\
\hline $\mathrm{ZnCl}_{2}+$ apo-HLA & $46.25 \pm 0.61$ & 47.55 \\
\hline $\mathrm{CdCl}_{2}+$ apo-HLA & $47.33 \pm 0.17$ & 51.25 \\
\hline $\mathrm{CoCl}_{2}+$ apo-HLA & $54.96 \pm 0.38$ & 56.31 \\
\hline $\mathrm{MnCl}_{2}+$ apo-HLA & $55.33 \pm 0.15$ & 55.84 \\
\hline $\mathrm{SrCl}_{2}+$ apo-HLA & $57.93 \pm 0.28$ & 57.30 \\
\hline $\mathrm{CaCl}_{2}+$ apo-HLA & $63.59 \pm 0.33$ & 64.42 \\
\hline $\mathrm{NaCl}^{\text {apo-HLA }}$ & $28.99 \pm 0.29$ & 26.88 \\
\hline $\mathrm{KCl}+$ apo-HLA & $29.75 \pm 0.69$ & 26.82 \\
\hline
\end{tabular}

Table 3. Summary of thermodynamic parameters for apo-HLA and metal-ion bound HLA at $37^{\circ} \mathrm{C}$

\begin{tabular}{|c|c|c|c|}
\hline Experiment & $\Delta \mathrm{H}(\mathrm{kJ} / \mathrm{mol})$ & $\Delta \mathrm{G}(\mathrm{kJ} / \mathrm{mol})$ & $\Delta \mathrm{S}(\mathrm{kJ} / \mathrm{mol} * \mathrm{~K})$ \\
\hline Apo-HLA & $184.92 \pm 20.78$ & $-5.29 \pm 0.81$ & $0.61 \pm 0.07$ \\
\hline $\mathrm{MgCl}_{2}+$ apo-HLA & $174.05 \pm 5.72$ & $4.10 \pm 0.17$ & $0.55 \pm 0.02$ \\
\hline $\mathrm{ZnCl}_{2}+$ apo-HLA & $121.84 \pm 6.02$ & $3.62 \pm 0.13$ & $0.38 \pm 0.02$ \\
\hline $\mathrm{CdCl}_{2}+$ apo-HLA & $181.79 \pm 11.56$ & $6.06 \pm 0.46$ & $0.57 \pm 0.04$ \\
\hline $\mathrm{CoCl}_{2}+$ apo-HLA & $184.69 \pm 10.47$ & $10.68 \pm 0.44$ & $0.56 \pm 0.03$ \\
\hline $\mathrm{MnCl}_{2}+$ apo-HLA & $238.65 \pm 15.22$ & $14.10 \pm 0.88$ & $0.72 \pm 0.05$ \\
\hline $\mathrm{SrCl}_{2}+$ apo-HLA & $223.41 \pm 10.61$ & $15.08 \pm 0.91$ & $0.67 \pm 0.03$ \\
\hline $\mathrm{CaCl}_{2}+$ apo-HLA & $232.16 \pm 14.87$ & $19.91 \pm 1.33$ & $0.68 \pm 0.04$ \\
\hline $\mathrm{NaCl}+$ apo-HLA $^{\mathrm{KCl}}+$ apo-HLA & $162.17 \pm 6.27$ & $-4.19 \pm 0.18$ & $0.54 \pm 0.02$ \\
\hline & & & \\
\hline
\end{tabular}

\subsection{Derivation of Thermodynamic Expressions for $\Delta H$, $\Delta G$ and $\Delta S$ Using Dose-Response Curve Equation}

Using the does-response equation discussed in the communication, the mathematical expressions for the thermodynamic parameters $(\Delta \mathrm{H}, \Delta \mathrm{G}$ and $\Delta \mathrm{S})$ of the conformation change upon thermal denaturation were derived. In this derivation, A represents the folded state and B represents the unfolded state. Starting with the general dose-response equation where $\mathrm{y}$ is the $\lambda_{\max }$ or fluorescence intensity and $\mathrm{x}$ is the temperature in Kelvin:

$$
y=A_{1}+\frac{A_{2}-A_{1}}{1+10^{\left(\log x_{0}-x\right) \cdot p}}
$$

If a two-state model $(\mathrm{A} \rightleftharpoons \mathrm{B})$ is assumed, the expression for the equilibrium constant can be written as follows:

$$
\mathrm{K}=\frac{\mathrm{B}}{\mathrm{A}}
$$


The variables were normalized to yield the fraction (f) of unfolded protein using the following relationship,

$$
\mathrm{f}=\frac{\mathrm{y}-\mathrm{y}_{\min }}{\mathrm{y}_{\max }-\mathrm{y}_{\min }}
$$

where $y_{\min }$ and $y_{\max }$ represent the bottom asymptote and top asymptote of either $\lambda_{\max }$ or fluorescence intensity curve, respectively. Substituting y into the fraction expression and simplifying,

$$
f=\frac{A_{1}+\frac{A_{2}-A_{1}}{1+10\left(T_{m}-T\right) \cdot p}-A_{1}}{A_{2}-A_{1}}=\frac{1}{1+10^{\left(T_{m}-T\right) \cdot p}}
$$

The concentrations of A and B can be expressed in terms of the fraction and the total concentration $\mathrm{C}$ which remains constant.

$$
\begin{array}{r}
A=(1-f) \cdot C \\
B=f \cdot C
\end{array}
$$

Substituting (5) and (6) into (4) and rearranging,

$$
\begin{gathered}
\mathrm{K}=\frac{\mathrm{f} \cdot \mathrm{C}}{(1-\mathrm{f}) \cdot \mathrm{C}}=\frac{\mathrm{f}}{1-\mathrm{f}}=\frac{\frac{1}{\left.1+10^{(\mathrm{T}}-\mathrm{T}\right) \cdot \mathrm{p}}}{1-\frac{1}{1+10^{\left(\mathrm{T}_{\mathrm{m}}-\mathrm{T}\right) \cdot \mathrm{p}}}}=\frac{\frac{1}{1+10^{\left(\mathrm{T}_{\mathrm{m}}-\mathrm{T}\right) \cdot \mathrm{p}}}}{\frac{10^{\left(\mathrm{T}_{\mathrm{m}}-\mathrm{T}\right) \cdot \mathrm{p}}}{1+10^{\left(\mathrm{T}_{\mathrm{m}}-\mathrm{T}\right) \cdot \mathrm{p}}}}= \\
\frac{1}{10^{\left(\mathrm{T}_{\mathrm{m}}-\mathrm{T}\right) \cdot \mathrm{p}}}=10^{\left(\mathrm{T}-\mathrm{T}_{\mathrm{m}}\right) \cdot \mathrm{p}}
\end{gathered}
$$

Taking logarithms on both sides,

$$
\log \mathrm{K}=\left(\mathrm{T}-\mathrm{T}_{\mathrm{m}}\right) \cdot \mathrm{p}
$$

Knowing $\log K=\ln K / \ln 10$ where $\ln 10 \approx 2.303$,

$$
\ln K=2.303 \cdot\left(T-T_{m}\right) \cdot p
$$

Differentiating with respect to $\mathrm{T}$,

$$
\frac{\mathrm{d} \operatorname{lnK}}{\mathrm{dT}}=2.303 \cdot \mathrm{p}
$$

The differential form of the van't Hoff equation is,

$$
\frac{\mathrm{d} \ln \mathrm{K}}{\mathrm{d}\left(\frac{1}{\mathrm{~T}}\right)}=-\mathrm{T}^{2} \cdot \frac{\mathrm{d} \ln \mathrm{K}}{\mathrm{dT}}=-\frac{\Delta \mathrm{H}}{\mathrm{R}}
$$

Using (10), an expression for $\Delta \mathrm{H}$ can be obtained by substituting and rearranging.

At equilibrium,

$$
\Delta \mathrm{H}=2.303 \cdot \mathrm{R} \cdot \mathrm{T}^{2} \cdot \mathrm{p}
$$

$$
\Delta \mathbf{G}=-\mathbf{R} \cdot \mathbf{T} \cdot \ln \mathbf{K}
$$

By substituting the $\operatorname{lnK}$ expression from (9), an expression for $\Delta \mathrm{G}$ can be obtained.

$$
\Delta \mathbf{G}=\mathbf{2 . 3 0 3} \cdot \mathbf{R} \cdot \mathbf{p} \cdot\left(\mathbf{T} \cdot \mathbf{T}_{\mathrm{m}}-\mathbf{T}^{2}\right)
$$

Since $\Delta \mathrm{G}=\Delta \mathrm{H}-\mathrm{T} \Delta \mathrm{S}$, an expression for $\Delta \mathrm{S}$ can be developed.

$$
\Delta S=\frac{\Delta H-\Delta G}{T}=\frac{2.303 \cdot R \cdot T^{2} \cdot p-\left[2.303 \cdot R \cdot p \cdot\left(T \cdot T_{m}-T^{2}\right)\right]}{T}
$$

which simplifies to

$$
\Delta \mathbf{S}=\mathbf{2 . 3 0 3} \cdot \mathbf{R} \cdot \mathbf{p} \cdot\left(\mathbf{2} \cdot \mathbf{T}-\mathbf{T}_{\mathbf{m}}\right)
$$

\subsection{Determination of Melting Temperature Using Fluo- rescence Intensities}

The following calculation was performed on apo-HLA + $\mathrm{ZnCl}_{2}$ experimental data (Figure 4) to show that it is possible to determine the transition temperature $\left(\mathrm{T}_{\mathrm{m}}\right)$ using the fluorescence intensity data instead of the $\lambda_{\max }$ data. The minimum fluorescence intensity was 105.1 a.u. at $40^{\circ} \mathrm{C}$, and the maximum fluorescence intensity was 130.1 a.u. at $55^{\circ} \mathrm{C}$ as shown in Figure 5. This indicates that the thermal transition takes place somewhere between these two temperature points. The top and bottom asymptotes can be generated by extending the local maximum towards the higher temperatures and by extending the local minimum towards the lower temperatures. A sigmoidal-shaped plot can then be produced, and a non-linear regression was then fitted to the plot using dose-response relationship as shown in Figure 5.

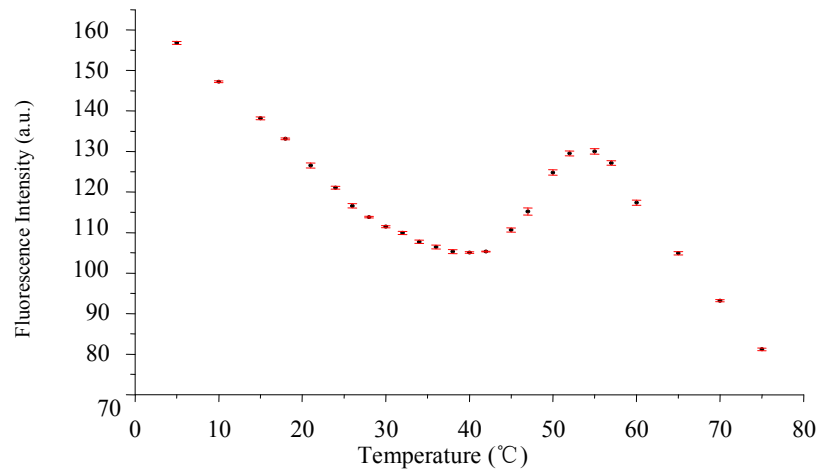

Figure 4. Sigmoidal transition curve of fluorescence intensity for $\mathrm{Zn}^{2+}$ bound HLA

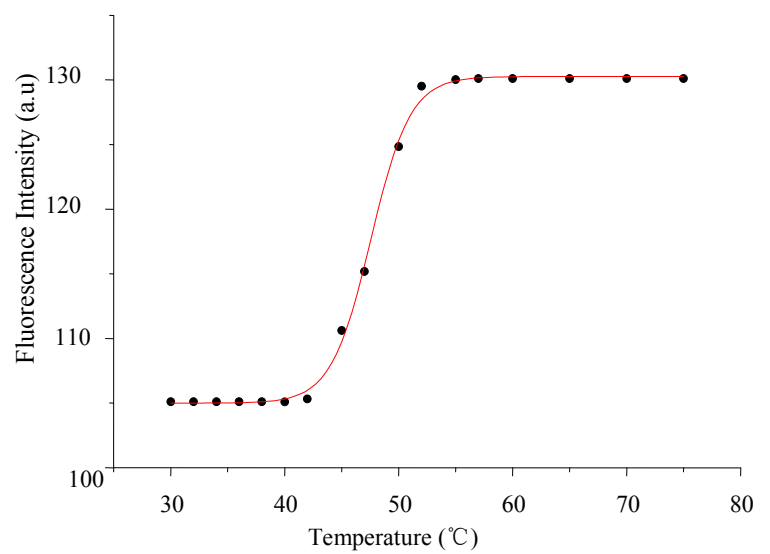

Figure 5. Sigmoidal transition curve of fluorescence intensity after data truncation

This shows an almost perfect sigmoidal transition with $\mathrm{R}^{2}$ value of 0.998 . Based on the fitting parameters generated by Origin data analysis software, the $T_{m}$ was determined to be $47.55^{\circ} \mathrm{C}$. The average of the $\mathrm{T}_{\mathrm{m}}$ calculated from the $\lambda_{\max }$ data of two apo-HLA $+\mathrm{ZnCl}_{2}$ experiments was $46.25^{\circ} \mathrm{C} \pm 0.61^{\circ} \mathrm{C}$. These two values are almost the same, and it is reasonable to suggest that this method of calculating the $\mathrm{T}_{\mathrm{m}}$ value is correct (Table 2).

\section{Discussion}

The substantial changes in the tryptophan fluorescence spectrum that occurred upon the removal of $\mathrm{Ca}^{2+}$ from human $\alpha$-lactalbumin (HLA) suggested that a major change in molecular conformation took place. It was also found by Kronman, et al.[7] that the conformational change resulting from the removal of $\mathrm{Ca}^{2+}$ was reversible as the addition of $\mathrm{Ca}^{2+}$ to the apo-bovine $\alpha$-lactalbumin (BLA) produced a 
return to an emission spectrum indistinguishable from that of the native protein (i.e. $\mathrm{Ca}^{2+}$ saturated BLA). Considering the fact that the amino acid sequence of HLA differs from that of BLA and GLA only by a few amino acid residues, similar results were expected to be produced from HLA. The profound difference in the tryptophan emission spectra (blue shift of a few nanometers in $\lambda_{\max }$ values upon metal ion binding) for apo-HLA and the metal-bound as shown in Figure 1 allowed us to investigate the binding properties of HLA to various metal ions.

The thermal stability of HLA in its apo form and in its metal-bound form can be determined by monitoring the wavelength at which the tryptophan fluorescence reaches a maximum $\left(\lambda_{\max }\right)$ as well as by monitoring the change in fluorescence intensity at a given wavelength. From the thermal denaturation experiments, it has clearly been indicated that the different metal ions (especially the divalent metal ions) stabilize HLA in a different way with the transition temperatures ranging from 28.15 to $63.59^{\circ} \mathrm{C}$. Upon heating, all the experiments performed with a different metal ion showed sigmoidal behavior, characteristic for a simple two-state transition with an increase in wavelength from 329 $\mathrm{nm}$ to $347.5 \mathrm{~nm}$ for divalent cation-bound HLA, from 332 $\mathrm{nm}$ to $346 \mathrm{~nm}$ for monovalent cation-bound HLA and from $333.5 \mathrm{~nm}$ to $346 \mathrm{~nm}$ for apo-HLA (Figure 3). The position of the shift in $\lambda_{\max }$ depended strongly upon the metal ion bound to the protein. All the divalent metal ions seemed to stabilize HLA because the $T_{m}$ was significantly greater than that of apo-HLA.

Table 4. Comparison of $T_{m}$ between HLA and GLA[4], as measured by fluorescence

\begin{tabular}{|c|c|c|}
\hline & \multicolumn{2}{|c|}{ Average $\mathrm{T}_{\mathrm{m}}\left({ }^{\circ} \mathrm{C}\right)$} \\
\hline Experiment & HLA & GLA [4] \\
\hline $\mathrm{Ca}^{2+}$ & $63.59 \pm 0.33$ & $66.71 \pm 0.19$ \\
\hline $\mathrm{Sr}^{2+}$ & $57.93 \pm 0.28$ & $59.78 \pm 0.17$ \\
\hline $\mathrm{Mg}^{2+}$ & $44.31 \pm 0.41$ & $55.68 \pm 0.23$ \\
\hline $\mathrm{Mn}^{2+}$ & $55.33 \pm 0.15$ & $54.15 \pm 0.15$ \\
\hline $\mathrm{Co}^{2+}$ & $54.96 \pm 0.38$ & $47.34 \pm 0.16$ \\
\hline $\mathrm{Cd}^{2+}$ & $47.33 \pm 0.17$ & $47.14 \pm 0.30$ \\
\hline $\mathrm{Zn}^{2+}$ & $46.25 \pm 0.61$ & $35.15 \pm 0.48$ \\
\hline $\mathrm{Apo}$ & $28.15 \pm 0.58$ & $31.30 \pm 0.33$ \\
\hline
\end{tabular}

As presented in Table 4, the melting temperatures obtained from this study on HLA have been compared to those obtained from the study done by Van Dael et al.[4] on GLA, which did not include experiments with monovalent cations. It is interesting to observe that some values of HLA are in good agreement with the corresponding values of GLA. There is a significant discrepancy in $\mathrm{T}_{\mathrm{m}}$ between GLA and HLA for $\mathrm{Mg}^{2+}, \mathrm{Co}^{2+}$ and $\mathrm{Zn}^{2+}$ metal ions. With respect to the apo-form, $\mathrm{Mg}^{2+}$ stabilizes GLA more than it does HLA whereas $\mathrm{Co}^{2+}$ and $\mathrm{Zn}^{2+}$ confer more stability to HLA than to GLA. As expected, for both studies, $\mathrm{Ca}^{2+}$ produced the largest $\mathrm{T}_{\mathrm{m}}\left(63.59^{\circ} \mathrm{C}\right)$ whereas apo-HLA had the smallest $\mathrm{T}_{\mathrm{m}}$ $\left(28.15^{\circ} \mathrm{C}\right)$. This means that the $\mathrm{Ca}^{2+} / \mathrm{HLA}$ complex is most stable one formed, and apo-HLA is relatively unstable. The results from the binding of the monovalent cations, $\mathrm{Na}^{+}$and
$\mathrm{K}^{+}$were somewhat inconclusive as the $\mathrm{T}_{\mathrm{m}}$ values were very close, and not significantly greater than that of apo-HLA $\left(28.99^{\circ} \mathrm{C}\right.$ for $\mathrm{Na}^{+}$and $29.75^{\circ} \mathrm{C}$ for $\left.\mathrm{K}^{+}\right)$. Taking the thermodynamic parameters into consideration, it is difficult to conclude that $\mathrm{Na}^{+}$or $\mathrm{K}^{+}$stabilized apo-HLA just because the $\mathrm{T}_{\mathrm{m}}$ was greater by about $1^{\circ} \mathrm{C}$.

According to our data analysis, it is possible to explain how close the biological systems are to equilibrium (i.e. $\Delta \mathrm{G}$ approaching zero). If $\Delta \mathrm{G}$ is positive, the system favors the folded state, whereas if $\Delta \mathrm{G}$ is negative, the system is likely in the unfolded state. Moreover, the greater the $\Delta \mathrm{G}$ is, the greater the probability of finding the system in the folded state. It follows that either state is equally likely when $\Delta \mathrm{G}$ is zero $\left(\right.$ at $\mathrm{T}_{\mathrm{m}}$ ), and the system spends $50 \%$ of its time in either state at equilibrium. Based on the analysis of the values of $\Delta \mathrm{G}$ at $37^{\circ} \mathrm{C}$, it can be concluded that $\mathrm{Na}^{+}$and $\mathrm{K}^{+}$would destabilize apo-HLA and are likely in the unfolded state. The complexes formed with the divalent metal ions would stabilize apo-HLA, and are likely to favor the folded state. The $\mathrm{Ca}^{2+}$-bound protein had the greatest value of $\Delta \mathrm{G}$ implying that the $\mathrm{Ca}^{2+} /$ apo-HLA complex is very stable, and it is likely that the system would be in the folded state. This conclusion is in good agreement with the $T_{m}$ results.

In Table 5 , the thermodynamic parameters $(\Delta \mathrm{H}, \Delta \mathrm{G}$ and $\Delta S$ ) obtained from this study on HLA have been compared to those obtained from the study done using the intrinsic fluorescence technique by Permyakov et al. [8] on BLA which examined the binding properties of $\mathrm{Ca}^{2+}, \mathrm{Mg}^{2+}, \mathrm{Na}^{+}$and $\mathrm{K}^{+}$. It is important to note that for HLA, the thermodynamic parameters were calculated based on the mathematical analysis that was derived in Section 3.1, whereas for BLA, they were determined based on graphical analysis of the van't Hoff equation (see equation 11), which relates the change in temperature to the change in the equilibrium constant and allows one determine the thermodynamic parameters graphically. As shown in Table 5, the results for HLA are comparable to those for BLA, but there are several interesting differences that should be pointed out. $\mathrm{Ca}^{2+}$ produced the highest $T_{m}$ in HLA. This implies that the degree of stabilization by $\mathrm{Ca}^{2+}$ binding is the greatest, and thus, it produced the largest $\Delta \mathrm{H}$. However, that is not the case in BLA. Although the $T_{m}$ was found to be greatest for $\mathrm{Ca}^{2+}$ binding, $\Delta \mathrm{H}$ was not necessarily the largest. The $\Delta \mathrm{H}$ of $\mathrm{Mg}^{2+}$ binding, which produced a $\mathrm{T}_{\mathrm{m}}$ of $45^{\circ} \mathrm{C}$, was almost $20 \%$ larger than that of $\mathrm{Ca}^{2+}$. This might suggest a different binding mechanism. In addition, the $\Delta \mathrm{H}$ of the apo form was found to be greater than that of $\mathrm{Na}^{+}$and $\mathrm{K}^{+}$in HLA whereas the opposite results were observed in BLA. It means that it would require less energy to unfold $\mathrm{Na}^{+}$/apo-HLA or $\mathrm{K}^{+} /$apo-HLA complex than the apo-HLA itself. Therefore, these results can suggest that $\mathrm{Na}^{+}$and $\mathrm{K}^{+}$destabilize HLA whereas they stabilize BLA. However, the fact that the $T_{m}$ value of $\mathrm{Na}^{+}$or $\mathrm{K}^{+}$-bound HLA was higher (though only by $1^{\circ} \mathrm{C}$ ) than that of apo-HLA was unexplainable as mentioned before. Taking the errors into account, the $\Delta \mathrm{S}$ values from both studies were also comparable. 
Table 5. Comparison of $\mathrm{T}_{\mathrm{m}}$ and thermodynamic parameters between HLA and BLA, as measured by fluorescence[8] and circular dichroism[5]

\begin{tabular}{|c|c|c|c|c|c|c|}
\hline & \multicolumn{3}{|c|}{$\mathrm{HLA}$} & \multicolumn{3}{c|}{$\mathrm{BLA}$} \\
\hline Experiment & $\mathrm{T}_{\mathrm{m}}\left({ }^{\circ} \mathrm{C}\right)$ & $\Delta \mathrm{H}(\mathrm{kJ} / \mathrm{mol})$ & $\Delta \mathrm{S}\left(\mathrm{kJ} / \mathrm{mol}{ }^{*} \mathrm{~K}\right)$ & $\left.\mathrm{T}_{\mathrm{m}}{ }^{\circ} \mathrm{C}\right)$ & $\Delta \mathrm{H}(\mathrm{kJ} / \mathrm{mol})$ & $\Delta \mathrm{S}\left(\mathrm{kJ} / \mathrm{mol}{ }^{*} \mathrm{~K}\right)$ \\
\hline $\mathrm{Ca}^{2+}$ & $63.59 \pm 0.33$ & $273.69 \pm 17.62$ & $0.81 \pm 0.05$ & $\begin{array}{c}62 \pm 1^{8} \\
58.57 \pm 0.12^{5}\end{array}$ & $\begin{array}{c}200.83 \pm 21^{8} \\
226.3 \pm 2.3^{5}\end{array}$ & $\begin{array}{c}0.73 \pm 0.04^{8} \\
0.69 \pm 0.07^{5}\end{array}$ \\
\hline $\mathrm{Mg}^{2+}$ & $44.31 \pm 0.41$ & $182.34 \pm 5.68$ & $0.57 \pm 0.02$ & $45 \pm 1^{8}$ & $238.49 \pm 21^{8}$ & $0.53 \pm 0.04^{8}$ \\
\hline $\mathrm{Na}^{+}$ & $28.99 \pm 0.29$ & $153.90 \pm 6.06$ & $0.51 \pm 0.02$ & $40 \pm 1^{8}$ & $167.36 \pm 21^{8}$ & $0.52 \pm 0.04^{8}$ \\
\hline $\mathrm{K}^{+}$ & $29.75 \pm 0.69$ & $146.94 \pm 8.87$ & $0.49 \pm 0.03$ & $41 \pm 1^{8}$ & $158.99 \pm 21^{8}$ & $0.54 \pm 0.04^{8}$ \\
\hline Apo & $28.15 \pm 0.58$ & $174.49 \pm 19.35$ & $0.58 \pm 0.06$ & $31 \pm 1^{8}$ & $154.81 \pm 21^{8}$ & $0.52 \pm 0.04^{8}$ \\
\hline
\end{tabular}

The values of thermodynamic parameters were also compared to those reported in the study done on BLA using circular dichroism by Kuwajima et al. [5]. Their analysis was performed only on the $\mathrm{Ca}^{2+}$ bound BLA based on the two-state denaturation model. Although there is small discrepancy, each parameter is in decent agreement with the corresponding values of BLA. The comparisons made with other studies that used different analysis techniques confirm the validity of the experimental and analytical methods that were used in this study.

\section{Conclusions}

The effects of the binding of various metal ions including $\mathrm{Mg}^{2+}, \mathrm{Zn}^{2+}, \mathrm{Cd}^{2+}, \mathrm{Co}^{2+}, \mathrm{Mn}^{2+}, \mathrm{Sr}^{2+}, \mathrm{Ca}^{2+}, \mathrm{Na}^{+}$and $\mathrm{K}^{+}$on the stability of the biologically important protein, human $\alpha$-lactalbumin (HLA), have been examined by means of the intrinsic tryptophan fluorescence. Based on the assumption of a simple two-state model, thermal-induced denaturation experiments revealed that the binding of the different metal ions stabilizes HLA with varying degree of stabilization for each ion. Heating induced a pronounced change in the tryptophan fluorescence intensity and a red shift of the spectrum towards longer wavelengths, which suggested a conformational change. The thermal transition curves generated by the experimental data produced a sigmoidal behavior which confirmed the two-state model. The analysis was then performed utilizing nonlinear regression fitting which in turn was used to determine the thermodynamic parameters $\left(\Delta \mathrm{H}, \Delta \mathrm{G}, \Delta \mathrm{S}\right.$ and $\left.\mathrm{T}_{\mathrm{m}}\right)$ based on the newly reported mathematical relationships.

Based on the data analysis, among those metal ions tested in this study, the monovalent cations $\mathrm{Na}^{+}$and $\mathrm{K}^{+}$were found to destabilize HLA whereas all the divalent cations were found to stabilize HLA. The extent of the stabilization was the greatest when HLA was bound to $\mathrm{Ca}^{2+}$ with a $\mathrm{T}_{\mathrm{m}}$ value of $63.59^{\circ} \mathrm{C}$ and a $\Delta \mathrm{G}$ of $19.91 \mathrm{~kJ} / \mathrm{mol}$ at physiological temperature. The results of thermodynamic parameters obtained from the present analysis have also been compared with those obtained from other studies in order to confirm their validity.

\section{ACKNOWLEDGEMENTS}

The authors would like to thank P. Chiu and V. Heinz for their assistance with this project.

\section{REFERENCES}

[1] Acharya, K.R.; Ren, J.S.; Stuart, D.I.; Phillips, D.C.; Fenna, R.E. Crystal structure of human alpha-lactalbumin at $1.7 \AA$ resolution. J. Mol. Biol. 1991, 221, 571-581

[2] Kuhn, N.J. Biochemistry of Lactation, Amesterdam: New York, NY, 1983

[3] Murakami, K.; Andree, P. J.; Berliner, L. J. Metal ion binding to alpha-lactalbumin species. Biochemistry. 1982, 21, 5488-5494

[4] Van Dael, D.; Chedad, A. An equilibrium and a kinetics stopped-flow fluorescence study of the binding of various metal ions to goat alpha-lactalbumin. J. Fluoresc. 2006, 16, $361-365$

[5] Kuwajima, K.; Sugai, S. Equilibrium and kinetics of the thermal unfolding of alpha-lactalbumin. The relation to its folding mechanism. Biophysical Chemistry. 1978, 8, 247-254

[6] Permyakov, E.A.; Burstein, E.A. Some aspects of studies of thermal transitions in proteins by means of their intrinsic fluorescence. Biophysical Chemistry, 1984, 19, 265-271

[7] Kronman, M.J.; Shinha, S.K.; Brew, K. Characteristics of the binding of $\mathrm{Ca}^{2+}$ and other divalent metal ions to bovine $\alpha$-lactalbumin. J. Biol. Chem, 1981, 256, 8582-8587

[8] Permyakov, E.A.; Morozova, L.A.; Burstein, E.A. Cation Binding Effects on the $\mathrm{pH}$, thermal and urea denaturation transitions in $\alpha$-lactalbumin. Biophysical Chemistry, 1985, 21, $21-31$

[9] Ramboarina, S.; Redfield, C. Probing the effect of temperature on the backbone dynamics of the human $\alpha$-lactalbumin molten globule. J. Am. Chem. Soc., 2008, 130(46), 15318-15326 